
\title{
25 Research Square \\ Evaluation of CSTB and DMBT1 Expression in Saliva of Gastric Cancer Patients and Controls
}

\section{Maryam Koopaie}

Tehran University of Medical Sciences

\section{Marjan Ghafourian}

Tehran University of Medical Sciences

Soheila Manifar ( $\nabla$ soheilaamanifar@gmail.com )

Imam Khomeini Hospital, Tehran University of Medical Sciences

\section{Shima Younespour}

Tehran University of Medical Sciences

\section{Mansour Davoudi}

Shiraz University

\section{Sajad Kolahdooz}

Universal Scientific Education and Research Network (USERN)

\section{Mohammad Shirkhoda}

Tehran University of Medical Sciences

\section{Research Article}

Keywords: CSTB, DMBT1, Saliva, Gastric cancer, Machine learning

Posted Date: September 7th, 2021

DOI: https://doi.org/10.21203/rs.3.rs-847012/v1

License: (c) (1) This work is licensed under a Creative Commons Attribution 4.0 International License.

Read Full License 


\section{Abstract}

Background: Gastric cancer (GC) is the fifth most common cancer and the third cause of cancer deaths globally with late diagnosis, low survival rate and poor prognosis. This case-control study aimed to evaluate the expression of cystatin B (CSTB) and deleted in malignant brain tumor 1 (DMBT1) in the saliva of GC patients with healthy individuals to construct diagnostic algorithms using statistical analysis and machine learning methods.

Methods: Demographic data, clinical characteristics and food intake habits of the case and control group were gathered through a standard checklist. Unstimulated whole saliva samples were taken from 31 healthy individuals and $31 \mathrm{GC}$ patients. Through ELISA test and statistical analysis, the expression of salivary CSTB and DMBT1 proteins were evaluated. To construct diagnostic algorithms, we used the machine learning method.

Results: The mean salivary expression of CSTB in GC patients was significantly lower $(115.55 \pm 7.06$, $p=0.001)$ and the mean salivary expression of DMBT1 in GC patients was significantly higher $(171.88 \pm 39.67, p=0.002)$ than the control. Multiple linear regression analysis demonstrated that $G C$ was significantly correlated with high levels of DMBT1 after controlling the effects of age of participants $\left(R^{2}=0.20, p<0.001\right)$. Considering salivary CSTB greater than $119.06 \mathrm{ng} / \mathrm{mL}$ as an optimal cut-off value, the sensitivity and specificity of CSTB in the diagnosis of GC was $83.87 \%$ and $70.97 \%$, respectively The area under the ROC curve was calculated as 0.728 . The optimal cut-off value of DMBT1 for differentiating GC patients from controls was greater than $146.33 \mathrm{ng} / \mathrm{mL}$ (sensitivity $=80.65 \%$ and specificity $=64.52 \%$ ). The area under the ROC curve was up to 0.741 . As a result of the machine learning method, the area under the receiver-operating characteristic curve for the diagnostic ability of CSTB, DMBT1, demographic data, clinical characteristics and food intake habits was 0.95 . The machine learning model's sensitivity, specificity, and accuracy were $100 \%, 70.8 \%$, and $80.5 \%$, respectively.

Conclusion: Salivary levels of DMBT1 and CSTB may be accurate in diagnosing GCs. Machine learning analyses using salivary biomarkers, demographic, clinical and nutrition habits data simultaneously could provide affordability models with acceptable accuracy for differentiation of GC by a cost-effective and non-invasive method.

\section{Introduction}

Gastric cancer (GC) is the sixth most common malignancy in the world. It is the third most common cause of cancer deaths. This cancer is $2-3$ fold more prevalent in men than women and the death rate is more incident in men [1]. The incidence of GC varies according to the geographical region and culture of each region. So that more than $50 \%$ of new cases occurring in developing countries, including Iran [2]. The most common type of cancer incidence and cancer mortality in men of Iranian people was GC [1, 2]. GC is a multifactorial disease caused by a combination of environmental factors and genetic changes [3, 4]. Environmental risk factors for this disease include smoking [5], alcohol [6], high salt intake [7], nitrite 
and nitrate in some foods [8], including processed meats, high consumption of red meat smoked foods, low consumption of raw fruits and vegetables containing vitamin $C$ and antioxidants $[9,10]$, overweight and obesity [11, 12], Helicobacter pylori [13, 14] and low socioeconomic conditions [15], including low education and low income [16-18]. Approximately $90 \%$ of gastric cancers are adenocarcinomas. NonHodgkin lymphomas and leiomyosarcomas make up the remaining $10 \%[19,20]$.

Photofluorography, serum pepsinogen concentration, serum ghrelin (low serum ghrelin may indicate a high risk of GC), gastrin 17, and gastric wall cell antibodies (associated with an increased risk of atrophic gastritis, which may play a role in GC) are among the non-invasive ways of screening for stomach cancer to date [21]. Endoscopic screening is cost-effective in high-prevalence areas, but in moderate-risk populations, there is no evidence that it is effective or cost-effective [22]. In addition, endoscopy is an invasive procedure in which the risk of bleeding, mucosa perforation and death has been reported. Imaging is also used to diagnose this cancer. Including computed tomography (CT), magnetic resonance imaging (MRI) and positron emission tomography (PET), each of which is used for a specific purpose [23]. The limitations of these advanced imaging technologies are the lack of widespread access, training issues in the interpretation of these "advanced" images technique, selection of imaging acquisition parameters and their diagnostic accuracies $[24,25]$. Although machine learning and artificial intelligence have led to advances in diagnostic imaging techniques, there are still challenges to the early detection of GC [26-28]. Prevention of GC may be achieved through primary prevention by reducing the incidence of $\mathrm{GC}$ or by using secondary prevention by early detection, identifying and treating the disease in its early stages [21,29]. Despite significant improvements in the survival of GC patients in recent decades, GC is often diagnosed at an advanced stage and has a poor prognosis due to the high prevalence of recurrence [30-33]. Since GC is symptomatic at high levels, early detection using effective screening methods is important in reducing mortality.

Biomarkers are factors that are objectively measured and evaluated as indicators of natural biological processes, pathogenic processes, or drug responses to a therapeutic intervention [31, 34-36]. Saliva is one of the most complex biological fluids in the body, reflecting a wide range of physiological conditions in the body [37, 38]. Compared to blood sampling or biopsy, using saliva has advantages, including accessible collection and storage, less invasiveness, cost-effectiveness and no need for specialized equipment [39]. In various studies, salivary proteins have been used as potential diagnostic markers and monitor the prognosis of disease, patient survival, and treatment [40-42].

Cystatin B (CSTB) is a protein structure encoded by the CSTB gene that acts as an intracellular thiol protease inhibitor [43]. This gene is located on chromosome 21q22.3 [44]. This protein belongs to the large family of cystatins (type two), which can form dimers stabilized by non-covalent forces and inhibit Papain and Cathepsins $\mathrm{L}, \mathrm{H}$ and $\mathrm{B}$, and is thought to play a role in protecting protease leakage from lysozymes $[45,46]$. Deleted in malignant brain tumor 1 (DMBT1) is a tumor-inhibiting gene located on chromosome 10q25.3-q26.1 to its inactivation in several medulloblastoma cell lines in comparison with normal cells [47-50]. It plays an important role in some biological reactions, such as the innate immune system and inflammation and the recognition and accumulation of bacteria by binding to various 
pathogens and host molecules. This protein may act as an epithelial differentiating factor and contribute to the polarization of epithelial cells. The DMBT1 protein is encoded by the DMBT1 gene and is a scavenger receptor cysteine-rich (SRCR) family $[47,51]$.

Nowadays, machine learning in healthcare is becoming more widely used [52]. Machine learning methods help us develop computer algorithms that can consider a set of variables and their complicated relationships to accomplish specific tasks such as modeling, classification and regression. Despite efforts to use artificial intelligence in the image-based diagnosis of GC [27, 53], artificial intelligence methods in the analysis and modeling GC biomarkers have been limited. This study aims to evaluate the application of salivary levels of CSTB and DMBT1 in GC diagnosis, considering the importance of early diagnosis of GC through convenient and noninvasive methods. This paper purpose using statistical analysis and machine learning methods were proposed to construct a diagnostic algorithm based on the salivary levels of CSTB and DMBT1, demographic data, clinical characteristics and food intake habits data.

\section{Methods}

\section{Ethical statement}

This study was approved by the Tehran University of Medical Sciences Ethical Committee (ethical code: IR.TUMS.DENTISTRY.REC.1398.003). After describing the study objectives, all participants signed the informed consent before participating in this study. All methods were performed in accordance with the relevant guidelines and regulations.

\section{Samples}

This case-control study was undertaken on 31 healthy individuals and 31 GC (adenocarcinoma) patients in early stages, referred to Imam Khomeini Hospital in Tehran. They have been diagnosed with GC by a gastroenterologist based on histopathological and endoscopic examination. The exclusion criteria for subjects were as follows: 1) Patients with known active dental and periodontal infections. 2) Patients with a known history of any other tumors and malignancies and any obvious inflammatory diseases such as liver cirrhosis, chronic renal disease, diabetes mellitus, and also any systemic diseases. 3) Patients with a known history of any surgical operations, chemotherapy, or radiotherapy before collecting saliva. 4) Patients with a history of receiving blood in the last three years. 5) Pregnant women. The control group was selected from healthy individuals referred to Imam Khomeini Hospital in Tehran for routine medical checkups. The enrolled people in control groups also had no active mouth infections, inflammation, malignancies, and systemic diseases. Pregnant women, people with a history of receiving blood in the last three years, and people with any history of cancer treatment were excluded from the control group. Gastric cancer patients and control were age- and sex-matched (Figure 1). 
All participants were asked to carefully respond to a valid, uniform, and standardized checklist to report their demographic characteristics (gender, age, education level and occupational stress) and habits that possibly affect GC progression. To ensure the validity and completeness of the responses, one of the trained authors supervised the completion of each questionnaire, which only explained items neutrally when necessary but did not offer any directive or indicative clues.

Participants' occupation was classified into three groups; high-stress level, moderate stress level, and lowstress level [54]. Farmers, manual laborers, and the unemployed are categorized in high-stress level, because of low income, commercial stress, and physical stress. Sales clerks, workers in service industries, security guards, and workers in transportation or communication industries are categorized in the moderate-stress level group. Professionals, administrators, and office clerks are categorized into the lowstress level group [54]. Smoking habit is defined as current smokers who are intermittent smoker (1>cigarettes per day (CPD)) or light smoker (1-10 CPD), moderate smoker (11-19 CPD), or heavy smoker $(20<C P D)$ [55]. All participants were further requested to report a positive history of gastroesophageal reflux disease (GERD), gastric ulcer, anemia, type of patient care (inpatient or outpatient), history of abdominal radiotherapy, frequency score (FS) for intake of vegetables/fruit, fast food, salty fish, preference score for salty taste, sour taste and spicy taste. FS was defined as 0 , never; $1,1 \geq$ time per month; 2, 2-3 times per month; 3, 1-2 times per week; 4, 3-4 times per week; 5, 5-6 times per week; 6, 1 time per day; 7, 2 times per day; 8,3 times per day; $9,4 \leq$ times per day. FS equal to 4 and higher was considered positive [54]. Preference score ranged from 1 (extremely dislike) to 7 (extremely like) with an increment of 1. Like and extremely like was considered positive [56].

\section{Saliva collection}

In order to prevent the possible effects of circadian rhythm changes on salivary secretions, saliva sampling was performed at 9:00 to 11:00 am. Participants were asked to abstain from eating and drinking, smoking and oral hygiene for 90 minutes before sampling to avoid salivary irritation. After dental and periodontal examination, sampling of whole non-stimulated saliva without mechanical and chemical stimulation was performed by spitting method. The person was asked to collect his saliva for 5 to 15 minutes at 60 -second intervals and pour saliva into pre-weighed sterile containers.

\section{Determination of salivary CSTB and DMBT1 levels}

Saliva samples were stored in $-80^{\circ} \mathrm{C}$ until enzyme-linked immunosorbent assay (ELISA) examination. ELISA test was performed by 96 test ELISA kit (ZellBio GmbH, Ulm, Germany) according to the manufacturer instructions. The absorbance of samples were measured using Hyperion ELISA microplate reader. The concentrations of CSTB and DMBT1 were determined by spectrometer software based on standard curves. 


\section{Statistical analysis methods}

Statistical analysis were performed using statistical software SPSS 18.0.0. (SPSS Inc. Chicago, IL, USA). P-values $(p)$ less than 0.05 were considered significant. Shapiro-Wilk test was used to examine the normality assumption of continuous variables. Descriptive statistics were reported as mean $\pm S D$ for quantitative variables and were summarized by number and percentages for qualitative variables. Quantitative variables were compared with students' t-test between the two groups. Spearman and Pearson correlation tests were applied for examining the association between two quantitative variables.

Multiple linear regression analysis was used to determine the parameters most predictive of the salivary CSTB and DMBT1. A stepwise forward regression algorithm was applied to select parameters to be entered in the final model. All variables which were significant in univariate analysis and biologically plausible to affect the continuous outcomes (salivary CSTB and DMBT1) were selected to be evaluated in the aforementioned algorithm. Only the variables that entered the model at $p$-values less than 0.1 were included in the final model. Univariate and multivariable logistic regression analyses were conducted to examine the association between the explanatory variables and the presence of GC.

Receiver operating characteristic (ROC) curve was constructed to assess the diagnostic values of salivary CSTB and DMBT1 for differentiating GC patients from healthy controls. MedCalc ${ }^{\circledR}$ Statistical Software version 19.8 (MedCalc Software Ltd, Ostend, Belgium; https://www.medcalc.org; 2021) was used to construct ROC curve and to find optimal cut-off value.

\section{Machine learning method}

To assess the effectiveness of CSTB and DMBT1 for GC prediction, we perform a set of machine learning analyses. For this aim, we extract demographic data, clinical characteristics and food intake status features in addition to CSTB and DMBT1. Also, we use another feature during the experiments, namely a which is derived as:

\section{$\alpha=\frac{\text { DMBT } 1}{\text { CSTB }}$}

We used an artificial neural network as a supervised machine learning method to predict GC. A multi-layer fully connected feed-forward neural network method was constructed to predict the label of data samples. For implementing the proposed model, we used Python Software Foundation, Version 3.7, and the Keras library [57], which is a high-level neural network API. During the training phase of the constructed method, for each training data sample, the extracted features, including DMBT1, CSTB, alpha (a) besides demographics, clinical characteristics and food intake status features, were normalized in the range of $[0,1]$ and were entered into the network. The output value indicates the label of the data sample. $80 \%$ of data samples were used during the training and validation phase, and $20 \%$ remaining were used 
during the test phase. We used the 4-fold cross-validation method and the Adam optimizer [58] as the optimization algorithm. Data samples were labeled as follows; GC patients were labeled 1 and control cases were labeled 0 . The constructed model has two hidden layers, and each hidden layer has 16 neurons. We used the ReLU activation function for the hidden layers, and the sigmoid activation function was used for the output layer. We also used binary cross-entropy as the loss function of the artificial neural network.

\section{Results}

\section{Patient characteristics}

Demographics, clinical characteristics and laboratory findings of patients with GC and healthy controls are summarized in Table 1. The two groups differed significantly according to educational level $(p<0.0001)$, occupational status $(p<0.0001)$, positive history of GERD $(p<0.0001)$, positive history of gastric ulcers $(p=0.01)$, vegetable consumption $(p=0.02)$ and salty taste preference $(p=0.02)$ (Table 1$)$.

However, no statistically significant difference was observed between patients with GC and healthy controls regarding gender, age, positive history of anemia, current smoking status, drug consumption, alcohol consumption, fast food consumption, salty fish consumption and sour and spicy taste preferences (Table 1).

\section{Salivary CSTB and DMBT1 concentrations}

The mean salivary CSTB level was significantly lower in GC patients in comparison with healthy controls $(p=0.001$, Table 1). The mean DMBT1 concentration was significantly higher in GC patients compared with healthy controls $(p=0.002$, Table 1$)$.

\section{Association between salivary CSTB levels and all evaluated variables}

Table 2 summarizes the mean salivary CSTB concentrations according to demographics, clinical characteristics and food intake status of participants in each study group. Spearman correlation test resulted in a significant positive association between age and salivary CSTB levels in healthy controls $(r=0.36$ and $p=0.046)$. However, no significant correlation was found between these two parameters in the patient group $(\mathrm{r}=0.32$ and $\mathrm{p}=0.08)$. In both study groups, no association was observed between salivary CSTB levels and other evaluated parameters in Table 2. According to the results of multiple linear regression, GC was significantly associated with low levels of salivary CSTB after controlling the effects of age of participants (adjusted $R^{2}=0.21, F=8.96$ and $p<0.001$ ). 


\section{Association between DMBT1 level and all other evaluated variables}

The mean DMBT1 levels according to demographics, clinical characteristics and food intake status of participants in each study group are presented in Table 2. No significant correlation was observed between age of participants and DMBT1 levels in both group $(r=0.33$ and $p=0.07$ in patients; $r=0.28$ and $\mathrm{p}=0.13$ in controls). In both groups, no association was found between DMBT1 concentration and each of the other explanatory variables in Table 2. Multiple linear regression analysis demonstrated that GC was significantly correlated with high levels of DMBT1 after controlling the effects of age of participants (adjusted $\mathrm{R}^{2}=0.20, \mathrm{~F}=8.67$ and $\mathrm{p}<0.001$ ).

\section{Association between salivary CSTB and DMBT1 levels}

There was no significant association between salivary CSTB and DMBT1 levels in patients with GC $(r=-0.04$ and $p=0.85)$ and healthy controls $(r=-0.18$ and $p=0.33)$.

\section{Association between evaluated variables and the risk of developing gastric cancer}

Based on univariate binary logistic regression, participants with higher educational level (odds ratio $(O R)=0.08 ; 95 \%$ confidence interval $(\mathrm{Cl})=0.02$ to 0.31$)$, with lower stress jobs $(\mathrm{OR}=0.04 ; 95 \% \mathrm{Cl}=0.01$ to $0.17)$ and with higher consumption of vegetables ( $\mathrm{OR}=0.26 ; 95 \% \mathrm{Cl}=0.08$ to 0.80$)$ were less likely to develop GC. Salty taste preference was significantly associated with risk of GC (OR=4.26; $95 \% \mathrm{Cl}=1.19$ to 15.25). Individuals with positive history of GERD were less likely to develop GC compared to whom without positive history of GERD (OR= $0.34 ; 95 \% \mathrm{Cl}=0.12$ to 0.97$)$. However, developing $\mathrm{GC}$ was not significantly correlated with age, gender, current smoking status, and sour and spicy taste preferences (Table 3). Individuals had 7\% reduction in the risk of GC per one-unit increase in salivary CSTB level (OR= $0.93 ; 95 \% \mathrm{Cl}=0.88$ to 0.97 , Table 3). A 0.02 -fold increased risk of GC was found per one-unit increase in level of DMBT1 $(\mathrm{OR}=1.02 ; 95 \% \mathrm{Cl}=1.01$ to 1.04 , Table 3$)$.

According to multivariable logistic regression analysis, salivary CSTB level (OR= $0.89 ; 95 \% \mathrm{Cl}=0.81$ to 0.98, $p=0.1$ ), DMBT1 level (OR=1.02; 95\% Cl= 1.00 to 1.05, $p=0.05)$, occupation status (OR (low vs. moderate-to-high stress level) $=0.07 ; 95 \% \mathrm{Cl}=0.01$ to $0.40, \mathrm{p}=0.003$ ) and educational level (OR (Diploma and higher vs. primary and secondary) $=0.03 ; 95 \% \mathrm{Cl}=0.003$ to $0.29, \mathrm{p}=0.003$ ) were the significant determinants of developing GC.

\section{The ROC curve for differentiating gastric cancer patients from healthy controls}


ROC curve was constructed to estimate diagnostic values of DMBT1 for differentiating GC patients from healthy controls. The results showed that the area under the ROC curve was up to $0.741(95 \% \mathrm{Cl}=0.614$ to $0.844 ; p<0.001$ and Figure 2). The optimal cut-off value for differentiating GC patients from healthy controls was DMBT1 levels greater than $146.33 \mathrm{ng} / \mathrm{mL}$ with which the sensitivity and specificity were $80.65 \%$ and $64.52 \%$, respectively.

In addition, a ROC curve was constructed to estimate diagnostics values of salivary CSTB. The optimal cut-off point for differentiating GC patients from healthy controls was salivary CSTB levels equal to or lower than $119.06 \mathrm{ng} / \mathrm{mL}$. At this cut-off point, the sensitivity and specificity were $83.87 \%$ and $70.97 \%$, respectively. The area under the ROC curve was calculated as $0.728(95 \% \mathrm{Cl}=0.60$ to $0.83 ; \mathrm{p}=0.002)$. Comparing the accuracy of salivary CSTB and DMBT1 in detecting GC indicated no significant difference between these diagnostic tests for differentiating the GC patients from healthy individuals (difference between areas $=0.01,95 \% \mathrm{Cl}=-0.170$ to $0.19 ; \mathrm{p}=0.89$, Figure 2 ). The optimal cut-off point of a (DMBT1/CSTB) for distinction GC patients from controls was equal to or lower than 1.157 (Figure 3). At this cut-off point, the sensitivity and specificity were $90.00 \%$ and $72.41 \%$, respectively.

\section{Machine learning analysis}

In order to analyze the DMBT1, CSTB and a features, we constructed five models with various input feature vectors. The input feature vector of the model (1) includes all the extracted features; The input feature vector of the model (2) includes all the extracted features, except DMBT1 and a; The input feature vector of the model (3) includes all the extracted features, excluding CSTB and $a$; The input feature vector of the model (3) includes all the extracted features, excluding CSTB and a. ROC curve analysis of all models is depicted in Figure 3.

The area under ROC curve (ACU) of the models revealed that model (1) achieves the highest AUC with the value of 0.95 . Elimination of DMBT1, CSTB, and a in the input feature vector causes the AUCs of models (2) and (3) to be reduced by 0.02 and 0.09 , respectively. The AUC of the model (4), wherein the DMBT1, CSTB, and a features have been removed from the input feature vector, is 0.89 . Our analysis shows that the AUC of the model (5), in which the input feature vector is composed of DMBT1, CSTB, and features codrmpared to the first model, merely reduces by 0.04 , which indicates the effectiveness of these three features in GC diagnosing. Figure 4 compares the sensitivity and specificity of constructed models on different cut-off point values.

Table 4 summarizes the sensitivity, specificity, positive predictive value (PPV), negative predictive value (NPV), accuracy, and AUC measures of constructed models. For this experiment, we set the cut-off point value for all the models to 0.3 to increase the sensitivity and reduce the prediction error of patient cases.

\section{Discussion}


GC is one of the major health problems in the world. Most cases of GCs are diagnosed in the later stages of the disease and become symptomatic in an advanced stage, while there is no formal screening program for the diseases. Although several screening approaches have been proposed, such as detecting gastric mucosal atrophy by measuring pepsinogens in the bloodstream, none of these methods are usually applied due to the nature of the disease and the deterioration of patients [59,60]. Despite potential preventive measures and screening methods such as PET-CT and endoscopy, no effective method has been proposed for future clinical trials to reduce GC [61, 62]. Endoscopy and biopsy of the gastric remain the standard diagnostic criteria for GC $[61,63]$. Due to the invasiveness of this method and the high cost and difficult access to this diagnostic method, endoscopy cannot be considered a suitable method for screening GC [64].

Biomarkers may serve as a non-invasive diagnosis in the early detection of $\mathrm{GC}$, but due to the nature of GC, no specific and sensitive biomarkers are yet available [65]. It is possible to determine these biomarkers in blood, urine, and saliva that saliva can provide the appropriate way to detect patients, better prognosis, prevent recurrence, and control patient mortality [66]. Several studies have used salivary proteins as potential diagnostic markers to monitor disease, prognosis, patient survival, and treatment [67-69]. It has also been shown that there are blood transfusions in saliva; therefore, it is almost equal to serum $[70,71]$.

CSTB is a protease inhibitor of cathepsin that is increased in cancer and acts as an intracellular thiol protease inhibitor [72, 73]. Evidence suggests the role of CSTB in various diseases [45, 74]. Animal models have been shown to increase the expression of CSTB inhibiting GC metastasis by involving biological processes involved in proliferation, apoptosis, and migration [75]. Overexpression of CSTB suppresses activation of the $\mathrm{PI3K} / \mathrm{Akt} / \mathrm{mTOR}$ pathway. $\mathrm{PI3K} / \mathrm{Akt} / \mathrm{mTOR}$ pathway is widely involved in regulating cell processes, including angiogenesis, cell proliferation and metabolism $[45,76]$. CSTB Downregulation promotes the development and progression of GC by affecting cell proliferation and migration. Previous studies have shown that CSTB plays different roles in ovarian cancer $[77,78]$, colon cancer [43], and myoclonic epilepsy [79].

This study indicated that salivary CSTB in GC patients was significantly lower than in the control group. Furthermore, this biomarker had an acceptable sensitivity (83.87\%) and specificity (70.97\%) in GC differentiation from the healthy control. Previous studies have shown that CSTB downregulates both protein and mRNA levels in GC and can be used as a marker in GC diagnosis [24]. Xiao et al. examined the salivary proteome of patients with GC. Five proteins were selected for further study, including interleukin-1 receptor antagonist (ILIRA), CSTB, isomerase triphosphate (TPI1) and DMBT1. ELISA examination of these proteins showed that their expression varied significantly in GC patients and healthy individuals with $85 \%$ sensitivity and $80 \%$ specificity in diagnosing GC [80].

The DMBT1 gene encodes a protein involved in cell proliferation and is considered a tumor suppressor for the brain and epithelial cancer [81-84]. Some studies have shown conflicting results in reducing or increasing the expression of DMBT1 in various cancers $[85,86]$. Preliminary studies have shown that 
DMBT1 is eliminated or reduced in a variety of tumors [87]. DMBT1 mucosal levels increase significantly (2.5-fold) in patients with gastric mucosal dysplasia and atrophic gastric mucosa [47]. An increase was seen in advanced gastritis associated with Helicobacter pylori infection. In addition, the increased expression of DMBT1 wa observed in precancerous lesions of the gastric mucosa and the role of DMBT1 in gastric carcinogenesis is complex $[47,88]$. Conde et al. showed that DMBT1 downregulates mRNA levels in $38 \%$ of GC patients and upregulates in $62 \%$ of GC patients. Loss of DMBT1 is likely to occur in differentiated GCs, while DMBT1 upregulation occurs in all types of GC [89]. Increased expression of DMBT1 in GC was shown in several studies, which confirms our results. Considering the acceptable sensitivity and specificity of salivary DMBT1 in GC detection, DMBT1 may be suggested as a noninvasive marker in GC detection.

Our results showed a significant relationship between consumption of a diet containing fruits and vegetables with GC. Thus, low consumption of vegetables and fruits is associated with an increased risk of GC. These results are in line with Wang et al., who stated that high fruit intake might decrease the risk of non-cardia GC [90]. According to ours, there is a relationship between salty taste preference and GC. Lin et al., in their study, stated that salt taste preference in the diet showed a dose-response relationship with GC. Reducing salt and salt processed food in diets might be one practical measure to preventing GC [56]. Yang et al. stated a significant relationship between salt taste sensitivity threshold and GC [91]. Excessive consumption might act as a gastric mucosa stimulant, leading to atrophic gastritis, increased DNA synthesis, and cell proliferation, thereby providing the basis for GC incidence [3]. Our study indicated that higher consumption of vegetables was less likely to develop GC; this result is confirmed in several studies [92-95].

According to our results, a higher educational level is associated with a lower incidence of GC. Lower educational level is accompanied by risk factors such as Helicobacter pylori infection and lifestyle factors such as dietary habits, obesity, and cigarette smoking, which may increase the risk of GC [96-98]. These results are in line with Rota et al. and Lagergren et al. showed that the high level of education was associated with a modest decrease in the $\mathrm{GC}$ rate $[99,100]$.

Individuals with a positive history of GERD were less likely to develop GC than those without a positive history of GERD. These results are in contrast to other studies. They stated that a history of GERD is a risk factor for cardiac GC, which arises from dysplastic intestinal metaplasia, and one potentially involving dysplasia of the cardiac-type mucosa [21, 101-103]. One reason for the difference is the type of cancer examined in the present study and the low sample size compared with other studies.

Participants were classified regarding occupation in three groups; low-stress level, moderate-stress level, high-stress level. Participants with lower stress jobs were less likely to develop GC. These results were in line by Kuwahara et al. results [54]. Also, Eguchi et al. stated that individuals working in coal and tin mining, metal processing (particularly steel and iron), and rubber manufacturing industries had increased risks of GC [104]. Yoshinaga revealed that occupations and industries still impact men's and women's health in terms of mortality due to GC in Japan [105]. 
The sensitivity of CSTB in GC diagnosis is $83.87 \%$, and its specificity is $70.97 \%$. AUC is close to one, and it can be concluded that this protein has an acceptable function in diagnosing GC. Yang et al. examined serum markers for the diagnosis of GC. They showed COPS2, CTSF, NT5E, and TERF1 biomarkers with $95 \%$ diagnostic sensitivity and $92 \%$ specificity for differentiating GC patients from healthy individuals. They concluded that these four serum biomarkers could be used as a non-invasive diagnostic indicator for GC, and a combination of them could potentially be used as a predictor of overall GC survival [106].

In this study, in addition to studying demographic information and salivary level of CSTB and DMBT1, the relationship between demographic data by taking the Salivary CSTB and DMBT1 into account was investigated to diagnose GC. Applying the information mentioned above to a set of machine learning methods confirmed our achieved findings. Utilizing machine learning methods in cancer diagnosis improves diagnostic accuracy and introduces novel and complex cause-and-effect relationships, which is not easily possible by examining and receiving a patient's history [107-109]. Hirasawa et al. used a neural network for detecting GC in endoscopic images. They correctly diagnosed GC lesions with a sensitivity of $92.2 \%$ and a positive predictive value of $30.6 \%$ [53]. Although several studies have used machine learning and artificial intelligence to interpret patients' images to diagnose GC, the use of machine learning to analyze biomarkers as well as patient demographics has been limited.

Machine learning methods do not cause crucial factors to diagnose GC but help us develop computer algorithms that can consider a set of variables and their complicated relationship. Machine learning is known as the most common engine of artificial intelligence. By taking advantage of machine learning in clinical issues, many useful facilities in public health are provided. The best model of Liu et al. exactly predicted the risk of early GC with the accuracy of $77.84 \%$ and the AUC of 0.66 by data mining method of patients' demographic data using C5.0 decision tree algorithm [110]. Zhu et al. used machine learning analysis of demographic data in the diagnosis of GC. They stated that machine learning is a non-invasive method with a sensitivity of 87.0 , specificity of 84.1 , and AUC equal to 0.91 for GC diagnosis, reducing medical costs [111]. These results are in accord with ours, indicating the ability of machine learning to analyze demographic data.

Aslam et al. showed that using machine learning and support vector machine (SVM) for analysis the results of high-performance liquid chromatography-mass spectrometry (HPLC-MS) of saliva lead to overall acuracy of $97.18 \%$, specificity of $97.44 \%$, and sensitivity of $96.88 \%$ for diagnosis of GC [112]. In this study, in addition to statistical analysis of the salivary CSTB and DMBT1, using various machine learning methods, we simultaneously analyzed the CSTB and DMBT1 salivary levels as a non-invasive method as well as demographic data, clinical characteristics and nutrition habits of patients and control group.

\section{Conclusion}

This study was designed to evaluate the salivary expression levels of CSTB and DMBT1 in GC patients with healthy individuals. Using statistical analysis and various machine learning models based on the 
salivary CSTB and DMBT1 concentrations, demographic, clinical characteristics data and nutrition habits, differentiation criteria for detecting GC patients from healthy control were proposed. This study showed a significant difference between salivary expression levels of CSTB and DMBT1 proteins in healthy individuals and GC patients. The expression of CSTB in the saliva of patients with GC decreased significantly compared to its expression in the saliva of healthy individuals. The salivary expression levels of DMBT1 increased in GC cases rather than healthy control significantly. These two diagnostic biomarkers expressed in saliva can probably be used as a non-invasive method in GC's early diagnosis and prognosis. Among the demographic factors, education levels and occupational stress levels; Among the clinical characteristics data, history of GERD and the history of gastric ulcers; Among the food intake habits, vegetable consumption, and salty taste preference, there is a significant difference between GC case and control. Various machine learning analyses using biomarkers, demographic, clinical and nutrition habits data could provide affordability offer models with acceptable accuracy for differentiation of GC and control by a cost-effective and non-invasive method.

\section{Abbreviations}

Area under ROC curve (ACU)

Cigarettes per day (CPD)

Computed tomography (CT)

Confidence interval (Cl)

Cystatin B (CSTB)

Deleted in malignant brain tumor 1 (DMBT1)

Enzyme-linked immunosorbent assay (ELISA)

Frequency score (FS)

Gastric cancer (GC)

Gastroesophageal reflux disease (GERD)

High-performance liquid chromatography-mass spectrometry (HPLC-MS)

Magnetic resonance imaging (MRI)

Negative predictive value (NPV)

Odds ratio $(\mathrm{OR})$

Positive predictive value (PPV) 
Positron emission tomography (PET)

Receiver operating characteristic (ROC)

Scavenger receptor cysteine-rich (SRCR)

Support vector machine (SVM)

\section{Declarations}

\section{Ethics approval and consent to participate}

This study was approved by the Tehran University of Medical Sciences Ethical Committee (ethical code: IR.TUMS.DENTISTRY.REC.1398.003). After describing the study objectives, all participants signed the informed consent before participating in this study. All methods were performed in accordance with the relevant guidelines and regulations.

\section{Consent for publication}

Not applicable.

\section{Availability of data and materials}

The datasets used and/or analyzed during the current study are available from the corresponding author on reasonable request. Machine learning code that was used is accessible via the following address:

https://codeberg.org/mansur/CSTB_and_DMBT1_gastric_cancer.git

\section{Competing interests}

The authors declare that they have no competing interests.

\section{Funding}

Theis study was supported by School of Dentistry, International Campus, Tehran University of Medical Sciences (Grant ID: 98-03-168-43709).

\section{Acknowledgements}

Not applicable 


\section{Authors' contributions}

MK, MG and SM conceived the study idea and led data collection. MK, MG, and SM created the study protocol and wrote the original draft. MK and SY contributed to data analysis / interpretation and preparation of the manuscript. MK, MG, SY and MD led the writing- review \& editing. MD and SK performed machine learning. MK, SY, MS and SM interpreted the results. All authors read and approved the final manuscript.

\section{References}

1. Sung H, Ferlay J, Siegel RL, Laversanne M, Soerjomataram I, Jemal A, Bray F: Global cancer statistics 2020: GLOBOCAN estimates of incidence and mortality worldwide for 36 cancers in 185 countries. CA: a cancer journal for clinicians 2021, 71(3):209-249.

2. Bray F, Ferlay J, Soerjomataram I, Siegel RL, Torre LA, Jemal A: Global cancer statistics 2018: GLOBOCAN estimates of incidence and mortality worldwide for 36 cancers in 185 countries. CA: a cancer journal for clinicians 2018, 68(6):394-424.

3. Yusefı AR, Lankarani KB, Bastani P, Radinmanesh M, Kavosi Z: Risk factors for gastric cancer: a systematic review. Asian Pacific journal of cancer prevention: APJCP 2018, 19(3):591.

4. Rugge M: Gastric cancer risk: between genetics and lifestyle. The Lancet Oncology 2020, 21(10):1258-1260.

5. Li W-Y, Han Y, Xu H-M, Wang Z-N, Xu Y-Y, Song Y-X, Xu H, Yin S-C, Liu X-Y, Miao Z-F: Smoking status and subsequent gastric cancer risk in men compared with women: a meta-analysis of prospective observational studies. BMC cancer 2019, 19(1):1-12.

6. Everatt R, Tamosiunas A, Kuzmickiene I, Virviciute D, Radisauskas R, Reklaitiene R, Milinaviciene E: Alcohol consumption and risk of gastric cancer. a cohort study of men in Kaunas, Lithuania, with up to 30 years follow-up. BMC cancer 2012, 12(1):1-11.

7. Eusebi LH, Telese A, Marasco G, Bazzoli F, Zagari RM: Gastric cancer prevention strategies: a global perspective. Journal of gastroenterology and hepatology 2020, 35(9):1495-1502.

8. Zhang F-X, Miao Y, Ruan J-G, Meng S-P, Dong J-D, Yin H, Huang Y, Chen F-R, Wang Z-C, Lai Y-F: Association between nitrite and nitrate intake and risk of gastric cancer: a systematic review and meta-analysis. Medical science monitor: international medical journal of experimental and clinical research 2019, 25:1788.

9. Katagiri R, Goto A, Shimazu T, Yamaji T, Sawada N, Iwasaki M, Inoue M, Tsugane S, Group JPHCbPS: Dietary fiber intake and risk of gastric cancer: The Japan Public Health Center-based prospective study. International Journal of Cancer 2021, 148(11):2664-2673.

10. Wang F, He M-M, Wang Z-X, Li S, Jin Y, Ren C, Shi S-M, Bi B-T, Chen S-Z, Lv Z-D: Phase I study of highdose ascorbic acid with mFOLFOX6 or FOLFIRI in patients with metastatic colorectal cancer or gastric cancer. BMC cancer 2019, 19(1):1-10. 
11. Sahakyan MA, Shahbazyan SS, Martirosyan A, Gabrielyan A, Petrosyan H, Sahakyan AM: Gastrectomy for Gastric Cancer in Patients with BMI $\geq 30$ kg/m2. The American Surgeon 2020, 86(2):158-163.

12. Hashimoto Y, Hamaguchi M, Obora A, Kojima T, Fukui M: Impact of metabolically healthy obesity on the risk of incident gastric cancer: a population-based cohort study. BMC endocrine disorders 2020, 20(1):1-7.

13. Ghotaslou R, Leylabadlo HE, Nasiri MJ, Dabiri H, Hashemi A: Risk of gastric cancer in association with Helicobacter pylori different virulence factors: A systematic review and meta-analysis. Microbial pathogenesis 2018, 118:214-219.

14. Kpoghomou M-A, Wang J, Wang T, Jin G: Association of Helicobacter pylori babA2 gene and gastric cancer risk: a meta-analysis. BMC cancer 2020, 20:1-7.

15. Sarfati D, Gurney J, Stanley J, Koea J: A retrospective cohort study of patients with stomach and liver cancers: the impact of comorbidity and ethnicity on cancer care and outcomes. BMC cancer 2014, 14(1):1-11.

16. Yin J, Wu X, Li S, Li C, Guo Z: Impact of environmental factors on gastric cancer: a review of the scientific evidence, human prevention and adaptation. journal of environmental sciences 2020 , 89:65-79.

17. Rawla P, Barsouk A: Epidemiology of gastric cancer: global trends, risk factors and prevention. Przeglad gastroenterologiczny 2019, 14(1):26.

18. Venerito M, Vasapolli R, Rokkas T, Malfertheiner P: Gastric cancer: epidemiology, prevention, and therapy. Helicobacter 2018, 23:e12518.

19. Lyons K, Le LC, Pham YT-H, Borron C, Park JY, Tran CT, Tran TV, Tran HT-T, Vu KT, Do CD: Gastric cancer: epidemiology, biology, and prevention: a mini review. European Journal of Cancer Prevention 2019, 28(5):397-412.

20. Dong J, Thrift AP: Alcohol, smoking and risk of oesophago-gastric cancer. Best Practice \& Research Clinical Gastroenterology 2017, 31(5):509-517.

21. Karimi P, Islami F, Anandasabapathy S, Freedman ND, Kamangar F: Gastric cancer: descriptive epidemiology, risk factors, screening, and prevention. Cancer Epidemiology and Prevention Biomarkers 2014, 23(5):700-713.

22. Shah SC, Canakis A, Peek Jr RM, Saumoy M: Endoscopy for Gastric Cancer Screening is Costeffective for Asian Americans in the United States. Clinical Gastroenterology and Hepatology 2020.

23. Wang Z, Chen J-Q: Imaging in assessing hepatic and peritoneal metastases of gastric cancer: a systematic review. BMC gastroenterology 2011, 11(1):1-14.

24. Giganti F, Tang L, Baba H: Gastric cancer and imaging biomarkers: Part 1-a critical review of DWMRI and CE-MDCT findings. European radiology 2019, 29(4):1743-1753.

25. Borggreve AS, Goense L, Brenkman HJ, Mook S, Meijer GJ, Wessels FJ, Verheij M, Jansen EP, van Hillegersberg R, van Rossum PS: Imaging strategies in the management of gastric cancer: current role and future potential of MRI. The British journal of radiology 2019, 92(1097):20181044. 
26. He YS, Su JR, Li Z, Zuo XL, Li YQ: Application of artificial intelligence in gastrointestinal endoscopy. Journal of digestive diseases 2019, 20(12):623-630.

27. Niu P-H, Zhao L-L, Wu H-L, Zhao D-B, Chen Y-T: Artificial intelligence in gastric cancer: Application and future perspectives. World Journal of Gastroenterology 2020, 26(36):5408.

28. Zhou C-M, Wang Y, Ye H-T, Yan S, Ji M, Liu P, Yang J-J: Machine learning predicts lymph node metastasis of poorly differentiated-type intramucosal gastric cancer. Scientific Reports 2021, 11(1):1-7.

29. Fock K: The epidemiology and prevention of gastric cancer. Alimentary pharmacology \& therapeutics 2014, 40(3):250-260.

30. Kono Y, Saito H, Miyauchi W, Shimizu S, Murakami Y, Shishido Y, Miyatani K, Matsunaga T, Fukumoto Y, Nakayama Y: Increased PD-1-positive macrophages in the tissue of gastric cancer are closely associated with poor prognosis in gastric cancer patients. BMC cancer 2020, 20(1):1-9.

31. Matsuoka T, Yashiro M: Biomarkers of gastric cancer: Current topics and future perspective. World journal of gastroenterology 2018, 24(26):2818.

32. Durães C, Almeida GM, Seruca R, Oliveira C, Carneiro F: Biomarkers for gastric cancer: prognostic, predictive or targets of therapy? Virchows Archiv 2014, 464(3):367-378.

33. Lordick F, Allum W, Carneiro F, Mitry E, Tabernero J, Tan P, Van Cutsem E, Van de Velde C, Cervantes A: Unmet needs and challenges in gastric cancer: the way forward. Cancer treatment reviews 2014, 40(6):692-700.

34. Abbas M, Faggian A, Sintali DN, Khan GJ, Naeem S, Shi M, Dingding C: Current and future biomarkers in gastric cancer. Biomedicine \& Pharmacotherapy 2018, 103:1688-1700.

35. Henry NL, Hayes DF: Cancer biomarkers. Molecular oncology 2012, 6(2):140-146.

36. Ji J, Chen J, Wang A, Zhang W, Ju H, Liu Y, Li L: KK-LC-1 may be an effective prognostic biomarker for gastric cancer. BMC cancer 2021, 21(1):1-8.

37. Pedersen A, Sørensen C, Proctor G, Carpenter G, Ekström J: Salivary secretion in health and disease. Journal of oral rehabilitation 2018, 45(9):730-746.

38. Kaczor-Urbanowicz KE, Martin Carreras-Presas C, Aro K, Tu M, Garcia-Godoy F, Wong DT: Saliva diagnostics-Current views and directions. Experimental Biology and Medicine 2017, 242(5):459472.

39. Zhang A, Sun H, Wang X: Saliva metabolomics opens door to biomarker discovery, disease diagnosis, and treatment. Applied biochemistry and biotechnology 2012, 168(6):1718-1727.

40. Shu J, Yu H, Li X, Zhang D, Liu X, Du H, Zhang J, Yang Z, Xie H, Li Z: Salivary glycopatterns as potential biomarkers for diagnosis of gastric cancer. Oncotarget 2017, 8(22):35718.

41. Rapado-González Ó, Martínez-Reglero C, Salgado-Barreira Á, Takkouche B, López-López R, SuárezCunqueiro MM, Muinelo-Romay L: Salivary biomarkers for cancer diagnosis: a meta-analysis. Annals of medicine 2020, 52(3-4):131-144. 
42. Shu J, Ma J, Ren X, Wang J, Wang Y, Zhang K, Yu H, Guo X, Li Z: The abnormal glycopatterns of salivary glycoproteins in Esophageal squamous cell carcinoma Patients. Frontiers in Chemistry 2021, 9.

43. Ma Y, Chen Y, Petersen I: Expression and epigenetic regulation of cystatin $B$ in lung cancer and colorectal cancer. Pathology-Research and Practice 2017, 213(12):1568-1574.

44. Joensuu T, Lehesjoki AE, Kopra O: Molecular background of EPM1-Unverricht-Lundborg disease. Epilepsia 2008, 49(4):557-563.

45. Zhang J, Shi Z, Huang J, Zou X: CSTB downregulation promotes cell proliferation and migration and suppresses apoptosis in gastric cancer SGC-7901 cell line. Oncology research 2016, 24(6):487.

46. Soond SM, Kozhevnikova MV, Frolova AS, Savvateeva LV, Plotnikov EY, Townsend PA, Han Y-P, Zamyatnin Jr AA: Lost or Forgotten: The nuclear cathepsin protein isoforms in cancer. Cancer letters 2019, 462:43-50.

47. Garay J, Piazuelo MB, Lopez-Carrillo L, Leal YA, Majumdar S, Li L, Cruz-Rodriguez N, Serrano-Gomez SJ, Busso CS, Schneider BG: Increased expression of deleted in malignant brain tumors (DMBT1) gene in precancerous gastric lesions: Findings from human and animal studies. Oncotarget 2017, 8(29):47076.

48. Madsen J, Sorensen GL, Nielsen O, Tornøe I, Thim L, Fenger C, Mollenhauer J, Holmskov U: A variant form of the human deleted in malignant brain tumor 1 (DMBT1) gene shows increased expression in inflammatory bowel diseases and interacts with dimeric trefoil factor 3 (TFF3). PloS one 2013, 8(5):e64441.

49. Brim H, Ashktorab H: Genomics of colorectal cancer in African Americans. Next generation, sequencing \& applications 2016, 3(2).

50. Shen S, Liu H, Wang Y, Wang J, Ni X, Ai Z, Pan H, Liu H, Shao Y: Long non-coding RNA CRNDE promotes gallbladder carcinoma carcinogenesis and as a scaffold of DMBT1 and C-IAP1 complexes to activating PI3K-AKT pathway. Oncotarget 2016, 7(45):72833.

51. Park HS, Kim BC, Yeo HY, Kim K-H, Yoo BC, Park JW, Chang HJ: Deleted in malignant brain tumor 1 is a novel prognostic marker in colorectal cancer. Oncology reports 2018, 39(5):2279-2287.

52. Waring J, Lindvall C, Umeton R: Automated machine learning: Review of the state-of-the-art and opportunities for healthcare. Artificial Intelligence in Medicine 2020, 104:101822.

53. Hirasawa T, Aoyama K, Tanimoto T, Ishihara S, Shichijo S, Ozawa T, Ohnishi T, Fujishiro M, Matsuo K, Fujisaki J: Application of artificial intelligence using a convolutional neural network for detecting gastric cancer in endoscopic images. Gastric Cancer 2018, 21(4):653-660.

54. Kuwahara A, Takachi R, Tsubono Y, Sasazuki S, Inoue M, Tsugane S: Socioeconomic status and gastric cancer survival in Japan. Gastric Cancer 2010, 13(4):222-230.

55. Park M, Min S, Cho YJ, Kim S, Kwon H, Joh H-K, Oh B, Oh S-W, Choi HC, Lee CM: Association between Low-Intensity Smoking and Metabolic Syndrome in Korean Men. Journal of the Korean Society for Research on Nicotine and Tobacco 2019, 10(2):89-98. 
56. Lin S-H, Li Y-H, Leung K, Huang C-Y, Wang X-R: Salt processed food and gastric cancer in a Chinese population. Asian Pacific Journal of Cancer Prevention 2014, 15(13):5293-5298.

57. Chollet F: keras. In.; 2015.

58. Kingma DP, Ba J: Adam: A method for stochastic optimization. ICLR 2015. arXiv preprint arXiv:141269802015, 9.

59. Pasechnikov V, Chukov S, Fedorov E, Kikuste I, Leja M: Gastric cancer: prevention, screening and early diagnosis. World journal of gastroenterology: WJG 2014, 20(38):13842.

60. Trivanovic D, Plestina S, Honovic L, Dobrila-Dintinjana R, Vlasic Tanaskovic J, Vrbanec D: Gastric cancer detection using the serum pepsinogen test method. Tumori Journal 2021:03008916211014961.

61. Ajani JA, D'Amico TA, Almhanna K, Bentrem DJ, Chao J, Das P, Denlinger CS, Fanta P, Farjah F, Fuchs CS: Gastric cancer, version 3.2016, NCCN clinical practice guidelines in oncology. Journal of the National Comprehensive Cancer Network 2016, 14(10):1286-1312.

62. Hamashima C, Group SR, Guidelines GDGfGCS: Update version of the Japanese guidelines for gastric cancer screening. Japanese journal of clinical oncology 2018, 48(7):673-683.

63. Sumiyama K: Past and current trends in endoscopic diagnosis for early stage gastric cancer in Japan. Gastric Cancer 2017, 20(1):20-27.

64. Saumoy M, Schneider Y, Shen N, Kahaleh M, Sharaiha RZ, Shah SC: Cost effectiveness of gastric cancer screening according to race and ethnicity. Gastroenterology 2018, 155(3):648-660.

65. Necula L, Matei L, Dragu D, Neagu Al, Mambet C, Nedeianu S, Bleotu C, Diaconu CC, ChivuEconomescu M: Recent advances in gastric cancer early diagnosis. World journal of gastroenterology 2019, 25(17):2029.

66. Setti G, Pezzi ME, Viani MV, Pertinhez TA, Cassi D, Magnoni C, Bellini P, Musolino A, Vescovi P, Meleti M: Salivary microRNA for diagnosis of cancer and systemic diseases: a systematic review. International journal of molecular sciences 2020, 21(3):907.

67. Buzalaf MAR, Ortiz AdC, Carvalho TS, Fideles SOM, Araújo TT, Moraes SM, Buzalaf NR, Reis FN: Saliva as a diagnostic tool for dental caries, periodontal disease and cancer: is there a need for more biomarkers? Expert review of molecular diagnostics 2020, 20(5):543-555.

68. Farah R, Haraty H, Salame Z, Fares Y, Ojcius DM, Sadier NS: Salivary biomarkers for the diagnosis and monitoring of neurological diseases. Biomedical journal 2018, 41(2):63-87.

69. Tierney C, Bazou D, Lê G, Dowling P, O'Gorman P: Saliva-omics in plasma cell disorders-Proof of concept and potential as a non-invasive tool for monitoring disease burden. Journal of Proteomics 2021, 231:104015.

70. Javaid MA, Ahmed AS, Durand R, Tran SD: Saliva as a diagnostic tool for oral and systemic diseases. Journal of oral biology and craniofacial research 2016, 6(1):67-76.

71. Gniadek TJ, Pulkrabek S, Cohn CS: Measuring salivary blood: A potential in vivo assay to quantify platelet transfusion efficacy. Medical hypotheses 2017, 107:36-38. 
72. Xie Q, Liu L, Chen X, Cheng Y, Li J, Zhang X, Xu N, Han Y, Liu H, Wei L: Identification of Cysteine Protease Inhibitor CST2 as a Potential Biomarker for Colorectal Cancer. Journal of Cancer 2021, 12(17):5144.

73. Hölzen L, Parigiani MA, Reinheckel T: Tumor cell-and microenvironment-specific roles of cysteine cathepsins in mouse models of human cancers. Biochimica et Biophysica Acta (BBA)-Proteins and Proteomics 2020, 1868(7):140423.

74. Yan Y, Zhou K, Wang L, Wang F, Chen X, Fan Q: Clinical significance of serum cathepsin B and cystatin $\mathrm{C}$ levels and their ratio in the prognosis of patients with esophageal cancer. OncoTargets and therapy 2017, 10:1947.

75. Shu F, Zou X, Tuo H, She S, Huang J, Ren H, Hu H, Peng S, Wang J, Yang Y: Stathmin gene silencing suppresses proliferation, migration and invasion of gastric cancer cells via AKT/sCLU and STAT3 signaling. International journal of oncology 2019, 54(3):1086-1098.

76. Qiu C, Su W, Shen N, Qi X, Wu X, Wang K, Li L, Guo Z, Tao H, Wang G: MNAT1 promotes proliferation and the chemo-resistance of osteosarcoma cell to cisplatin through regulating PI3K/Akt/mTOR pathway. BMC cancer 2020, 20(1):1-12.

77. Takaya A, Peng WX, Ishino K, Kudo M, Yamamoto T, Wada R, Takeshita T, Naito Z: Cystatin B as a potential diagnostic biomarker in ovarian clear cell carcinoma. international journal of oncology 2015, 46(4):1573-1581.

78. Gashenko EA, Lebedeva VA, Brak IV, Tsykalenko EA, Vinokurova GV, Korolenko TA: Evaluation of serum procathepsin B, cystatin B and cystatin $C$ as possible biomarkers of ovarian cancer. International Journal of Circumpolar Health 2013, 72(1):21215.

79. Di Matteo F, Pipicelli F, Kyrousi C, Tovecci I, Penna E, Crispino M, Chambery A, Russo R, Ayo-Martin AC, Giordano M: Cystatin $B$ is essential for proliferation and interneuron migration in individuals with EPM 1 epilepsy. EMBO molecular medicine 2020, 12(6):e11419.

80. Xiao H, Zhang Y, Kim Y, Kim S, Kim JJ, Kim KM, Yoshizawa J, Fan L-Y, Cao C-X, Wong DT: Differential proteomic analysis of human saliva using tandem mass tags quantification for gastric cancer detection. Scientific reports 2016, 6(1):1-13.

81. Ma N, Zhao Y: DMBT1 suppresses cell proliferation, migration and invasion in ovarian cancer and enhances sensitivity to cisplatin through galectin-3/PI3k/Akt pathway. Cell Biochemistry and Function 2020, 38(6):801-809.

82. Müller H, Renner M, Helmke BM, Mollenhauer J, Felderhoff-Müser U: Elevated DMBT1 levels in neonatal gastrointestinal diseases. Histochemistry and cell biology 2016, 145(2):227-237.

83. Lu X, Xu Y, Zhao Y, Tao Q, Wu J: Silenced DMBT1 promotes nasal mucosa epithelial cell growth. Annals of human genetics 2018, 82(2):102-108.

84. Qu N, Shi R-L, Liao T, Huang S-L, Wen D, Hu J-Q, Zhang T-t, Han L-T, Ma B, Wang J: Germline missense mutation of Deleted in malignant brain tumor 1 (DMBT1) in familial mediastinal neuroendocrine cancer and in vitro effects in thyroid cancer cells. Neuroendocrinology 2020, 110(78):714-720. 
85. Zhang CX: The protective role of DMBT1 in cervical squamous cell carcinoma. The Kaohsiung journal of medical sciences 2019, 35(12):739-749.

86. Gan X-x, Li Y-y, Li S-j, Mo S-s, Feng J-h, Shen F, Cai W-s, Lai Y-q, Xu B: Significance of DMBT1 in Papillary Thyroid Carcinoma Concurrent With Hashimoto's Thyroiditis. Frontiers in Oncology 2021:2482.

87. Hoki T, Katsuta E, Yan L, Takabe K, Ito F: Low DMT1 expression associates with increased oxidative phosphorylation and early recurrence in hepatocellular carcinoma. journal of surgical research 2019 , 234:343-352.

88. Sousa JF, Ham A-JL, Whitwell C, Nam KT, Lee H-J, Yang H-K, Kim WH, Zhang B, Li M, LaFleur B: Proteomic profiling of paraffin-embedded samples identifies metaplasia-specific and early-stage gastric cancer biomarkers. The American journal of pathology 2012, 181(5):1560-1572.

89. Conde AR, Martins AP, Brito M, Manuel A, Ramos S, Malta-Vacas J, Renner M, Poustka A, Mollenhauer $\mathrm{J}$, Monteiro $\mathrm{C}$ : DMBT1 is frequently downregulated in well-differentiated gastric carcinoma but more frequently upregulated across various gastric cancer types. International journal of oncology 2007, 30(6):1441-1446.

90. Wang Z: Identification of Novel Modifiable Risk Factors of Gastric Adenocarcinoma. University of Pittsburgh; 2017.

91. Yang W-G, Chen C-B, Wang Z-X, Liu Y-P, Wen X-Y, Zhang S-F, Sun T-W: A case-control study on the relationship between salt intake and salty taste and risk of gastric cancer. World Journal of Gastroenterology: WJG 2011, 17(15):2049.

92. Zhou Y, Zhuang W, Hu W, Liu GJ, Wu TX, Wu XT: Consumption of large amounts of Allium vegetables reduces risk for gastric cancer in a meta-analysis. Gastroenterology 2011, 141(1):80-89.

93. Turati F, Pelucchi C, Guercio V, Vecchia CL, Galeone C: Allium vegetable intake and gastric cancer: A case-control study and meta-analysis. Molecular nutrition \& food research 2015, 59(1):171-179.

94. Ferro A, Costa AR, Morais S, Bertuccio P, Rota M, Pelucchi C, Hu J, Johnson KC, Zhang ZF, Palli D: Fruits and vegetables intake and gastric cancer risk: A pooled analysis within the Stomach cancer Pooling Project. International Journal of Cancer 2020, 147(11):3090-3101.

95. Vahid F, Davoodi SH: Nutritional factors involved in the etiology of gastric cancer: a systematic review. Nutrition and cancer 2021, 73(3):376-390.

96. Uthman OA, Jadidi E, Moradi T: Socioeconomic position and incidence of gastric cancer: a systematic review and meta-analysis. J Epidemiol Community Health 2013, 67(10):854-860.

97. Assaad S, Chaaban R, Tannous F, Costanian C: Dietary habits and Helicobacter pylori infection: a cross sectional study at a Lebanese hospital. BMC gastroenterology 2018, 18(1):1-13.

98. Rastaghi S, Jafari-Koshki T, Mahaki B, Bashiri Y, Mehrabani K, Soleimani A: Trends and risk factors of gastric cancer in Iran (2005-2010). International journal of preventive medicine 2019, 10.

99. Rota M, Alicandro G, Pelucchi C, Bonzi R, Bertuccio P, Hu J, Zhang ZF, Johnson KC, Palli D, Ferraroni $\mathrm{M}$ : Education and gastric cancer risk-An individual participant data meta-analysis in the StoP project consortium. International journal of cancer 2020, 146(3):671-681. 
100. Lagergren J, Andersson G, Talbäck M, Drefahl S, Bihagen E, Härkönen J, Feychting M, Ljung R: Marital status, education, and income in relation to the risk of esophageal and gastric cancer by histological type and site. Cancer 2016, 122(2):207-212.

101. Demicco EG, Farris AB, Baba Y, Agbor-Etang B, Bergethon K, Mandal R, Daives D, Fukuoka J, Shimizu $M$, Dias-Santagata $D$ : The dichotomy in carcinogenesis of the distal esophagus and esophagogastric junction: intestinal-type vs cardiac-type mucosa-associated adenocarcinoma. Modern Pathology 2011, 24(9):1177-1190.

102. Chen H-N, Wang Z, Li X, Zhou Z-G: Helicobacter pylori eradication cannot reduce the risk of gastric cancer in patients with intestinal metaplasia and dysplasia: evidence from a meta-analysis. Gastric Cancer 2016, 19(1):166-175.

103. Kim J-J: Upper gastrointestinal cancer and reflux disease. Journal of gastric cancer 2013, 13(2):7985.

104. Eguchi H, Wada K, Prieto-Merino D, Smith DR: Lung, gastric and colorectal cancer mortality by occupation and industry among working-aged men in Japan. Scientific reports 2017, 7(1):1-7.

105. Yoshinaga $\mathrm{Y}$, Tanaka $\mathrm{H}$, Wada $\mathrm{K}$, Ikeda S: Gastric cancer mortality rates by occupation and industry among male and female workers aged 25-64 years in Japan. Industrial health 2020.

106. Yang L, Wang J, Li J, Zhang H, Guo S, Yan M, Zhu Z, Lan B, Ding Y, Xu M: Identification of serum biomarkers for gastric cancer diagnosis using a human proteome microarray. Molecular \& Cellular Proteomics 2016, 15(2):614-623.

107. Poongodi P, Udayakumar E, Srihari K, Sachi NM: An Innovative Machine Learning Approach to Diagnose Cancer at an Early Stage. Data Analytics in Bioinformatics: A Machine Learning Perspective 2021:313-337.

108. Bu J, Lee TH, Poellmann MJ, Rawding PA, Jeong WJ, Hong RS, Hyun SH, Eun HS, Hong S: Tri-modal liquid biopsy: Combinational analysis of circulating tumor cells, exosomes, and cell-free DNA using machine learning algorithm. Clinical and Translational Medicine 2021, 11(8).

109. Kiritani S, Yoshimura K, Arita J, Kokudo T, Hakoda H, Tanimoto M, Ishizawa T, Akamatsu N, Kaneko J, Takeda S: A new rapid diagnostic system with ambient mass spectrometry and machine learning for colorectal liver metastasis. BMC cancer 2021, 21(1):1-9.

110. Liu M-M, Wen L, Liu Y-J, Cai Q, Li L-T, Cai Y-M: Application of data mining methods to improve screening for the risk of early gastric cancer. BMC medical informatics and decision making 2018, 18(5):23-32.

111. Zhu S-L, Dong J, Zhang C, Huang Y-B, Pan W: Application of machine learning in the diagnosis of gastric cancer based on noninvasive characteristics. Plos one 2020, 15(12):e0244869.

112. Aslam MA, Xue C, Wang K, Chen Y, Zhang A, Cai W, Ma L, Yang Y, Sun X, Liu M: SVM based classification and prediction system for gastric cancer using dominant features of saliva. Nano Biomed Eng 2020, 12(1):1-13.

\section{Tables}


Table 1. Demographics, clinical characteristics, food intake status and laboratory findings of patients with GC and healthy controls

\begin{tabular}{|c|c|c|c|}
\hline Characteristics & $\begin{array}{c}\text { GC patients } \\
(\mathbf{n}=\mathbf{3 1})\end{array}$ & $\begin{array}{l}\text { Healthy controls } \\
\qquad(n=31)\end{array}$ & $\mathbf{p}^{*}$ \\
\hline Gender & & & 0.12 \\
\hline Female & $4(12.90 \%)$ & $9(29.03 \%)$ & \\
\hline Male & $27(87.10 \%)$ & $22(70.97 \%)$ & \\
\hline Age, years & $63.42 \pm 11.40$ & $59.06 \pm 7.78$ & 0.08 \\
\hline Education levels & & & $<0.0001$ \\
\hline Primary and secondary & $28(90.32 \%)$ & $13(41.94 \%)$ & \\
\hline Diploma and BSc. & $3(9.68 \%)$ & $13(41.94 \%)$ & \\
\hline MSc. and $\mathrm{PhD}$. & $0(0.00 \%)$ & $5(16.13 \%)$ & \\
\hline Occupational stress levels & & & $<0.0001$ \\
\hline Low stress level & $6(19.35 \%)$ & $26(83.87 \%)$ & \\
\hline Moderate stress level & $23(74.19 \%)$ & $3(9.68 \%)$ & \\
\hline High stress level & $2(6.45 \%)$ & $2(6.45 \%)$ & \\
\hline \multicolumn{4}{|l|}{ Positive history of disease } \\
\hline GERD & $13(41.94 \%)$ & $21(67.74 \%)$ & 0.04 \\
\hline Gastric ulcers & $7(22.58 \%)$ & $0(0.00 \%)$ & 0.01 \\
\hline Anemia & $2(6.45 \%)$ & $0(0.00 \%)$ & 0.49 \\
\hline Types of patient care & - & - & - \\
\hline Inpatient & $7(22.58 \%)$ & - & - \\
\hline Outpatient & $24(77.42 \%)$ & - & - \\
\hline Current smoking status & $9(29.03 \%)$ & $10(32.26 \%)$ & 0.78 \\
\hline Drug consumption & $3(9.68 \%)$ & $4(12.90 \%)$ & 1.00 \\
\hline Alcohol consumption & $1(3.23 \%)$ & $1(3.23 \%)$ & 1.00 \\
\hline History of radiotherapy & $0(0.00 \%)$ & $0(0.00 \%)$ & - \\
\hline Vegetable consumption & $16(51.61 \%)$ & $25(80.65 \%)$ & 0.02 \\
\hline Fast food consumption & $0(0.00 \%)$ & $1(3.23 \%)$ & 1.00 \\
\hline Salty fish consumption & $2(6.45 \%)$ & $0(0.00 \%)$ & 0.49 \\
\hline Salty taste preference & $12(38.71 \%)$ & $4(12.90 \%)$ & 0.02 \\
\hline Sour taste preference & $8(25.81 \%)$ & $6(19.35 \%)$ & 0.54 \\
\hline Spicy taste preference & $9(29.03 \%)$ & $8(25.81 \%)$ & 0.78 \\
\hline Salivary CSTB, $n g / m L$ & $115.55 \pm 7.06$ & $128.30 \pm 18.06$ & 0.001 \\
\hline Salivary DMBT1, $n g / m L$ & $171.88 \pm 39.67$ & $139.76 \pm 39.05$ & 0.002 \\
\hline
\end{tabular}

Values are expressed as mean \pm SD or No. (\%).

* P-value (p) for the comparison between patients with GC and healthy control groups. 
Table 2. Salivary CSTB and DMBT1 levels according to demographics, clinical characteristics and food intake status of study groups

\begin{tabular}{|c|c|c|c|c|}
\hline \multirow[b]{2}{*}{ Characteristics } & \multicolumn{2}{|c|}{ Salivary CSTB level (ng/mL) } & \multicolumn{2}{|c|}{ DMBT1 level (ng/mL) } \\
\hline & $\begin{array}{l}\text { Patients with GC } \\
\qquad(n=31)\end{array}$ & $\begin{array}{l}\text { Healthy } \\
\text { Controls } \\
(n=31)\end{array}$ & $\begin{array}{l}\text { Patients with GC } \\
\qquad(\mathrm{n}=31)\end{array}$ & $\begin{array}{l}\text { Healthy } \\
\text { Controls } \\
(n=31)\end{array}$ \\
\hline \multicolumn{5}{|l|}{ Gender } \\
\hline Female & $113.52 \pm 4.27$ & $135.21 \pm 20.07$ & $166.50 \pm 35.23$ & $134.22 \pm 28.52$ \\
\hline Male & $115.86 \pm 7.40$ & $125.47 \pm 16.84$ & $172.68 \pm 40.83$ & $142.03 \pm 43.01$ \\
\hline P-value & 0.40 & 0.22 & 0.76 & 0.56 \\
\hline \multicolumn{5}{|l|}{ Education } \\
\hline Primary and secondary & $115.67 \pm 7.41$ & $134.35 \pm 14.06$ & $169.84 \pm 40.05$ & $149.13 \pm 40.76$ \\
\hline Diploma and above & $114.48 \pm 2.37$ & $123.92 \pm 19.69$ & $190.89 \pm 36.69$ & $133.00 \pm 37.46$ \\
\hline$P$-value $\#$ & 0.56 & 0.10 & 0.43 & 0.27 \\
\hline \multicolumn{5}{|l|}{ Occupation } \\
\hline Low stress & $114.74 \pm 3.81$ & $129.96 \pm 17.32$ & $179.72 \pm 34.17$ & $136.86 \pm 39.31$ \\
\hline Moderate-to-high stress & $115.75 \pm 7.69$ & $119.62 \pm 21.44$ & $170.00 \pm 41.29$ & $154.87 \pm 37.95$ \\
\hline$P$-value & 0.56 & 0.36 & 0.56 & 0.37 \\
\hline \multicolumn{5}{|l|}{ History of GERD } \\
\hline Yes & $115.24 \pm 4.22$ & $130.12 \pm 18.47$ & $173.87 \pm 31.89$ & $145.95 \pm 43.24$ \\
\hline No & $115.78 \pm 8.68$ & $124.47 \pm 17.47$ & $170.44 \pm 45.32$ & $126.77 \pm 25.52$ \\
\hline P-value & 0.56 & 0.42 & 0.81 & 0.13 \\
\hline \multicolumn{5}{|l|}{ History of gastric ulcers } \\
\hline Yes & $116.21 \pm 7.80$ & - & $168.86 \pm 39.08$ & - \\
\hline $\mathrm{No}$ & $115.21 \pm 7.80$ & $128.30 \pm 18.06$ & $172.76 \pm 40.63$ & $139.76 \pm 39.05$ \\
\hline$P$-value & 0.48 & - & 0.82 & - \\
\hline \multicolumn{5}{|l|}{ Current smoking status } \\
\hline Yes & $115.66 \pm 4.00$ & $126.22 \pm 17.78$ & $177.56 \pm 59.71$ & $140.97 \pm 33.38$ \\
\hline No & $115.51 \pm 8.08$ & $129.29 \pm 18.54$ & $169.56 \pm 29.50$ & $139.19 \pm 42.25$ \\
\hline$P$-value & 0.95 & 0.66 & 0.71 & 0.90 \\
\hline \multicolumn{5}{|l|}{ Drug consumption } \\
\hline Yes & $109.58 \pm 19.24$ & $124.38 \pm 25.29$ & $140.78 \pm 58.58$ & $160.33 \pm 32.04$ \\
\hline No & $116.19 \pm 4.86$ & $128.88 \pm 17.31$ & $175.21 \pm 37.08$ & $136.72 \pm 39.58$ \\
\hline$P$-value & 0.61 & 0.75 & 0.42 & 0.25 \\
\hline \multicolumn{5}{|l|}{ Vegetable consumption } \\
\hline Yes & $114.57 \pm 8.40$ & $130.10 \pm 18.21$ & $169.42 \pm 47.02$ & $139.31 \pm 41.73$ \\
\hline No & $116.60 \pm 5.40$ & $120.78 \pm 16.74$ & $174.51 \pm 31.45$ & $141.67 \pm 28.05$ \\
\hline P-value & 0.43 & 0.26 & 0.72 & 0.87 \\
\hline \multicolumn{5}{|l|}{ Salty taste preference } \\
\hline Yes & $116.88 \pm 2.97$ & $122.58 \pm 28.86$ & $163.97 \pm 46.90$ & $143.75 \pm 21.21$ \\
\hline No & $114.72 \pm 8.71$ & $129.14 \pm 16.56$ & $176.88 \pm 34.79$ & $139.17 \pm 41.29$ \\
\hline$P$-value & 0.33 & 0.68 & 0.42 & 0.74 \\
\hline \multicolumn{5}{|l|}{ Sour taste preference } \\
\hline Yes & $114.92 \pm 12.19$ & $128.12 \pm 20.83$ & $163.67 \pm 30.18$ & $119.00 \pm 40.65$ \\
\hline No & $115.77 \pm 4.54$ & $128.34 \pm 17.81$ & $174.74 \pm 42.70$ & $144.75 \pm 37.79$ \\
\hline$P$-value & 0.85 & 0.98 & 0.44 & 0.20 \\
\hline \multicolumn{5}{|l|}{ Spicy taste preference } \\
\hline Yes & $117.95 \pm 5.61$ & $120.59 \pm 17.94$ & $173.41 \pm 45.27$ & $126.88 \pm 25.00$ \\
\hline No & $114.57 \pm 7.47$ & $130.98 \pm 17.70$ & $171.26 \pm 38.28$ & $144.25 \pm 42.42$ \\
\hline P-value ${ }^{\#}$ & 0.18 & 0.18 & 0.90 & 0.18 \\
\hline
\end{tabular}


Table 3. Results of univariate binary logistic regression analysis of the association between evaluated variables and the risk of developing $\mathrm{GC}$

\section{Characteristics}

Crude OR (95\% CI for OR)

\section{p}

\begin{tabular}{|c|c|c|}
\hline Age & $1.05(0.99$ to 1.10$)$ & 0.09 \\
\hline Gender (Female vs. male) & $0.36(0.10$ to 1.34$)$ & 0.13 \\
\hline Education (Diploma and higher vs. primary and secondary) & $0.08(0.02$ to 0.31$)$ & $<0.001$ \\
\hline Occupation (Low vs. moderate-to-high stress level) & $0.04(0.01$ to 0.17$)$ & $<0.0001$ \\
\hline Positive history of GERD & $0.34(0.12$ to 0.97$)$ & 0.04 \\
\hline Positive history of gastric ulcers* & - & - \\
\hline Positive history of anemia* & - & - \\
\hline Current smoking status & $0.86(0.29$ to 2.53$)$ & 0.78 \\
\hline Drug consumption & - & - \\
\hline Alcohol consumption* & - & - \\
\hline Vegetable consumption & $0.26(0.08$ to 0.80$)$ & 0.02 \\
\hline Fast food consumption* & - & - \\
\hline Salty fish consumption* & - & - \\
\hline Salty taste preference & $4.26(1.19$ to 15.25$)$ & 0.03 \\
\hline Sour taste preference & $1.45(0.44$ to 4.81$)$ & 0.54 \\
\hline Spicy taste preference & $1.18(0.38$ to 3.60$)$ & 0.78 \\
\hline Salivary CSTB, ng/mL & $0.93(0.88$ to 0.97$)$ & 0.003 \\
\hline Salivary DMBT1, ng/mL & $1.02(1.01$ to 1.04$)$ & 0.005 \\
\hline
\end{tabular}

* There was insufficient data for statistical analysis.

Table 4. Comparison of sensitivity, specificity, PPV, NPV, accuracy, and AUC machine learning models.

\begin{tabular}{cccccc} 
Measure & Model (1) & Model (2) & Model (3) & Mode (4) & Model (5) \\
\hline Sensitivity & $100 \%$ & $100 \%$ & $85.7 \%$ & $100 \%$ & $88.8 \%$ \\
\hline Specificity & $70.8 \%$ & $65.2 \%$ & $86.3 \%$ & $68.4 \%$ & $61.1 \%$ \\
\hline PPV & $63.0 \%$ & $6.01 \%$ & $80.0 \%$ & $73.9 \%$ & $69.5 \%$ \\
\hline NPV & $100 \%$ & $100 \%$ & $90.4 \%$ & $100 \%$ & $84.6 \%$ \\
\hline Accuracy & $80.5 \%$ & $77.0 \%$ & $86.1 \%$ & $83.3 \%$ & $75.0 \%$ \\
\hline AUC & 0.95 & 0.93 & 0.86 & 0.89 & 0.91
\end{tabular}

\section{Figures}




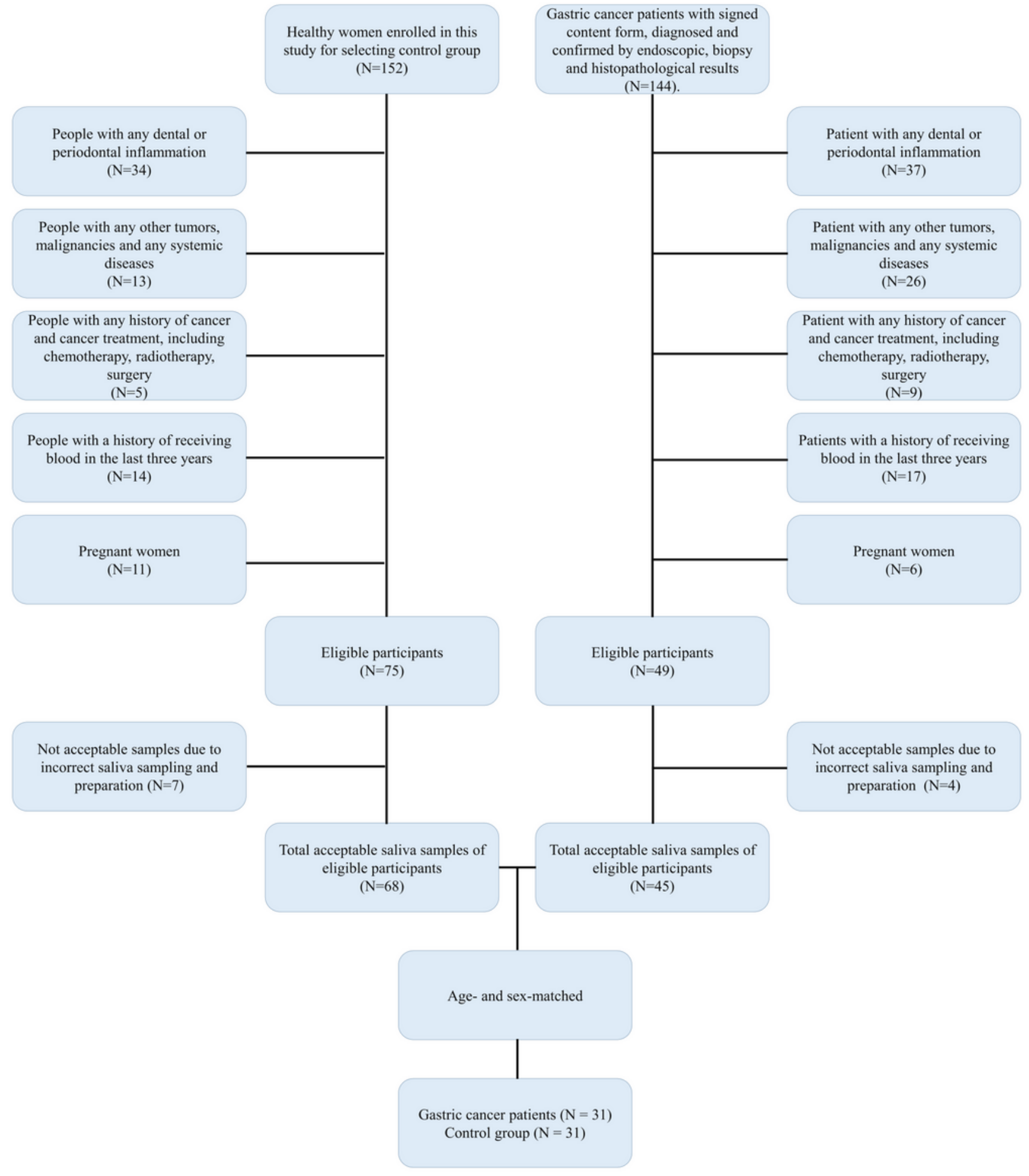

Figure 1

STARD flow diagram of the gastric cancer cases and control. 


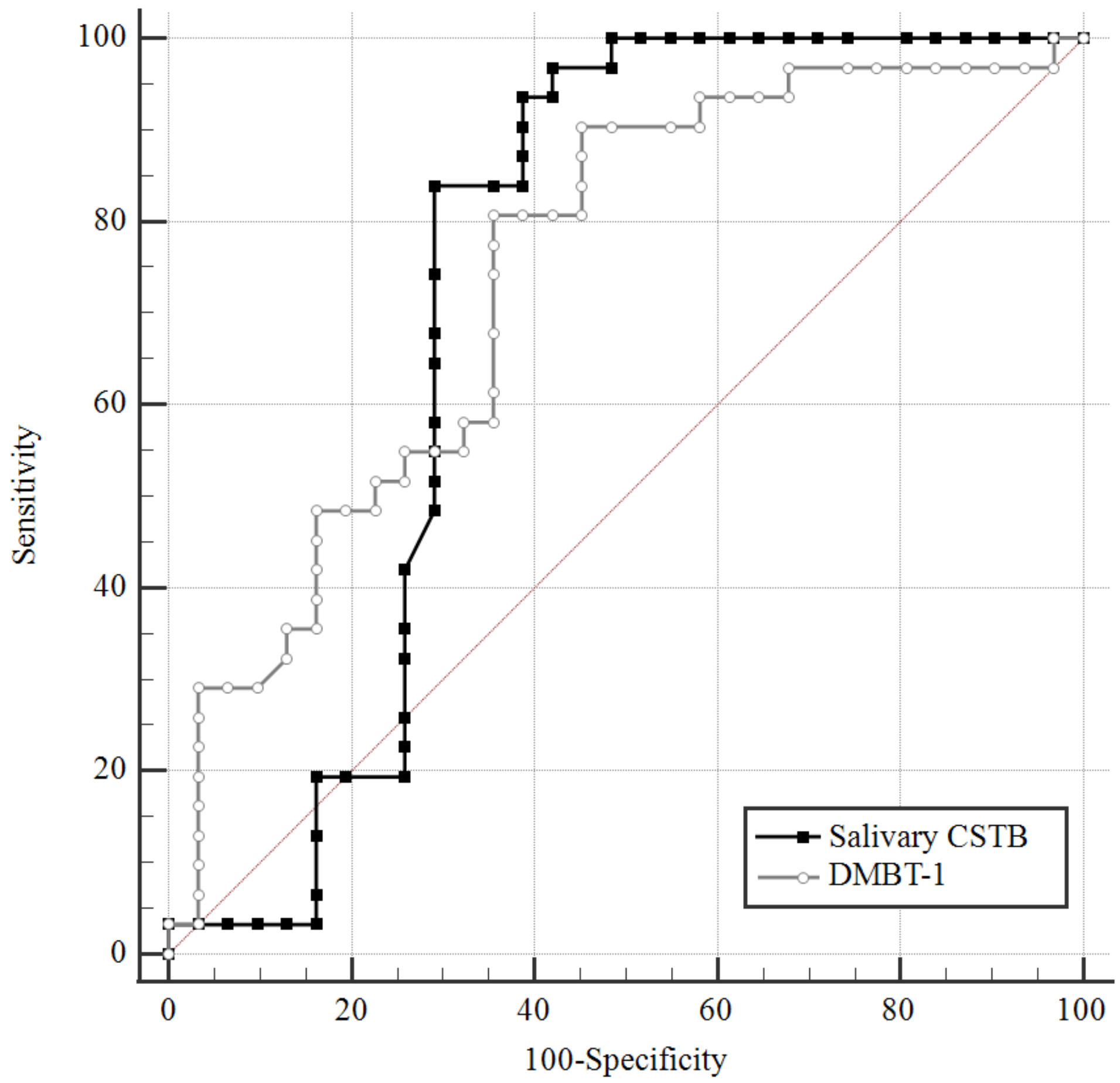

Figure 2

ROC curve for DMBT1 (AUC=0.741, sensitivity $=80.65 \%$, specificity $=64.52 \%$ ) and ROC curve for salivary CSTB (AUC $=0.728$, sensitivity $=83.87 \%$, specificity $=70.79 \%$ ) 
A) $\operatorname{CSTB}(\mathrm{ng} / \mathrm{ml})$

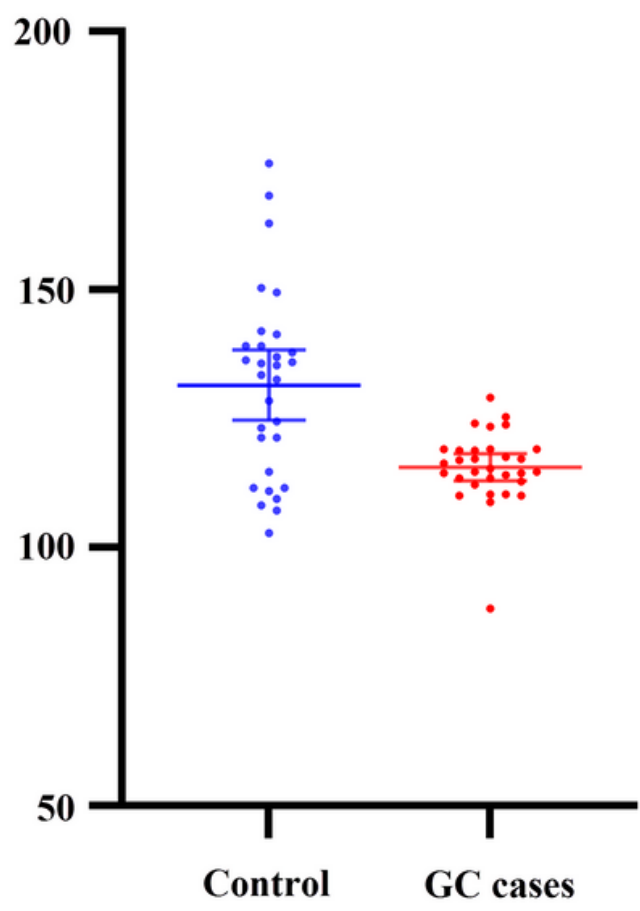

B) DMBT1 $(\mathrm{ng} / \mathrm{ml})$

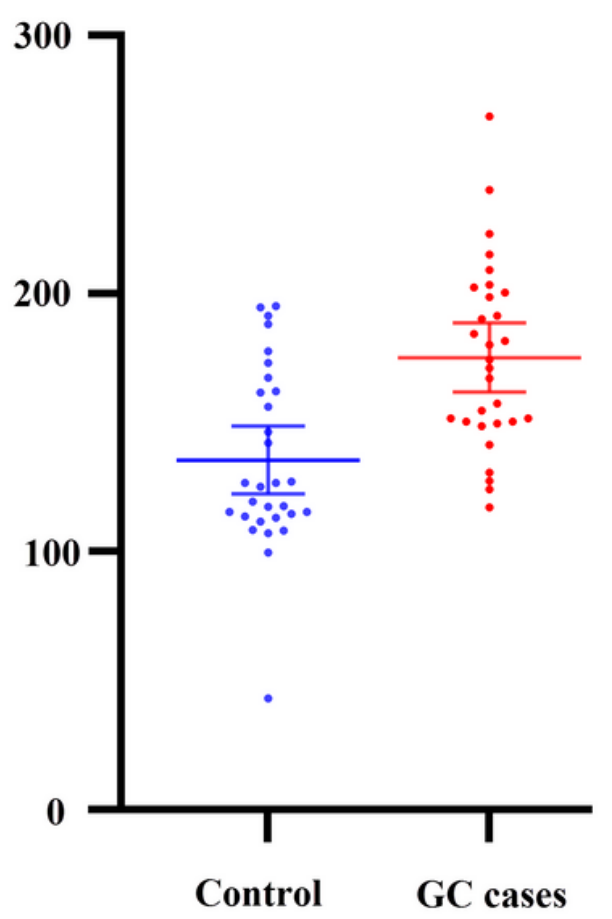

C) DMBT1/CSTB

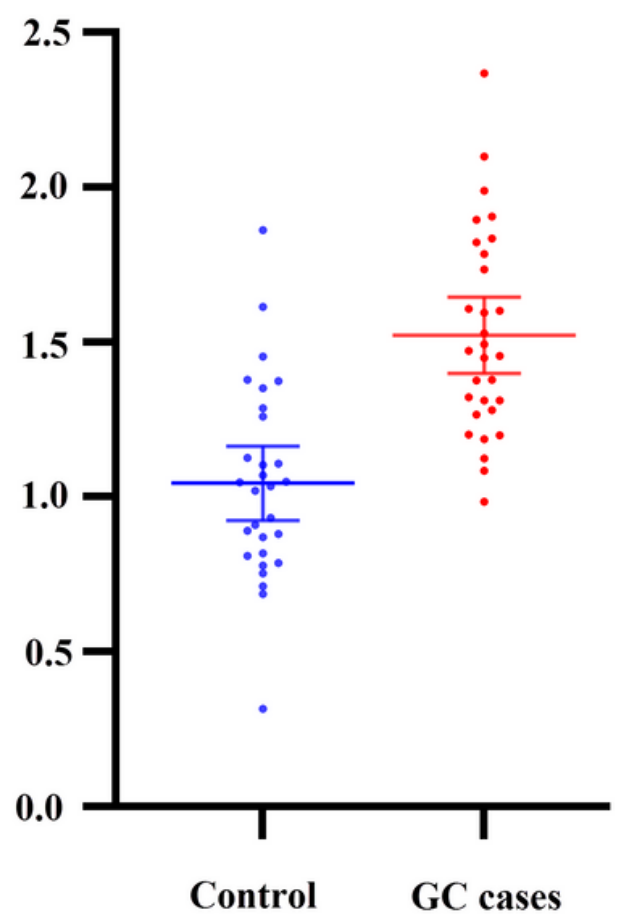

Figure 3

A) salivary CSTB levels in GC patients and control $(p<0.001), B)$ salivary DMBT1 levels in GC patients and control $(p<0.001)$, and C) salivary DMBT1/CSTB levels in GC patients and control $(p<0.001)$. 


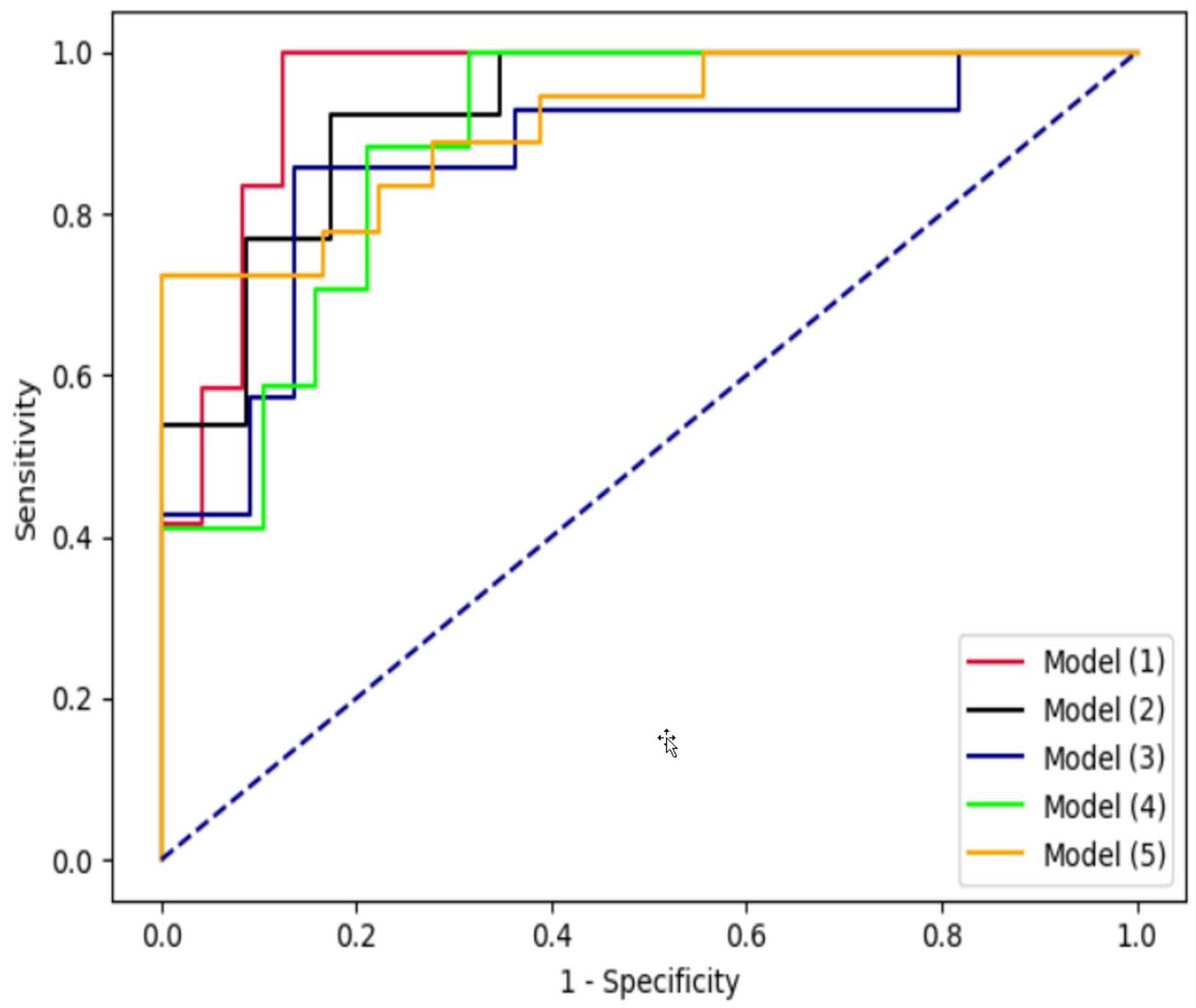

Figure 4

ROC curve analysis of five machine learning models. 

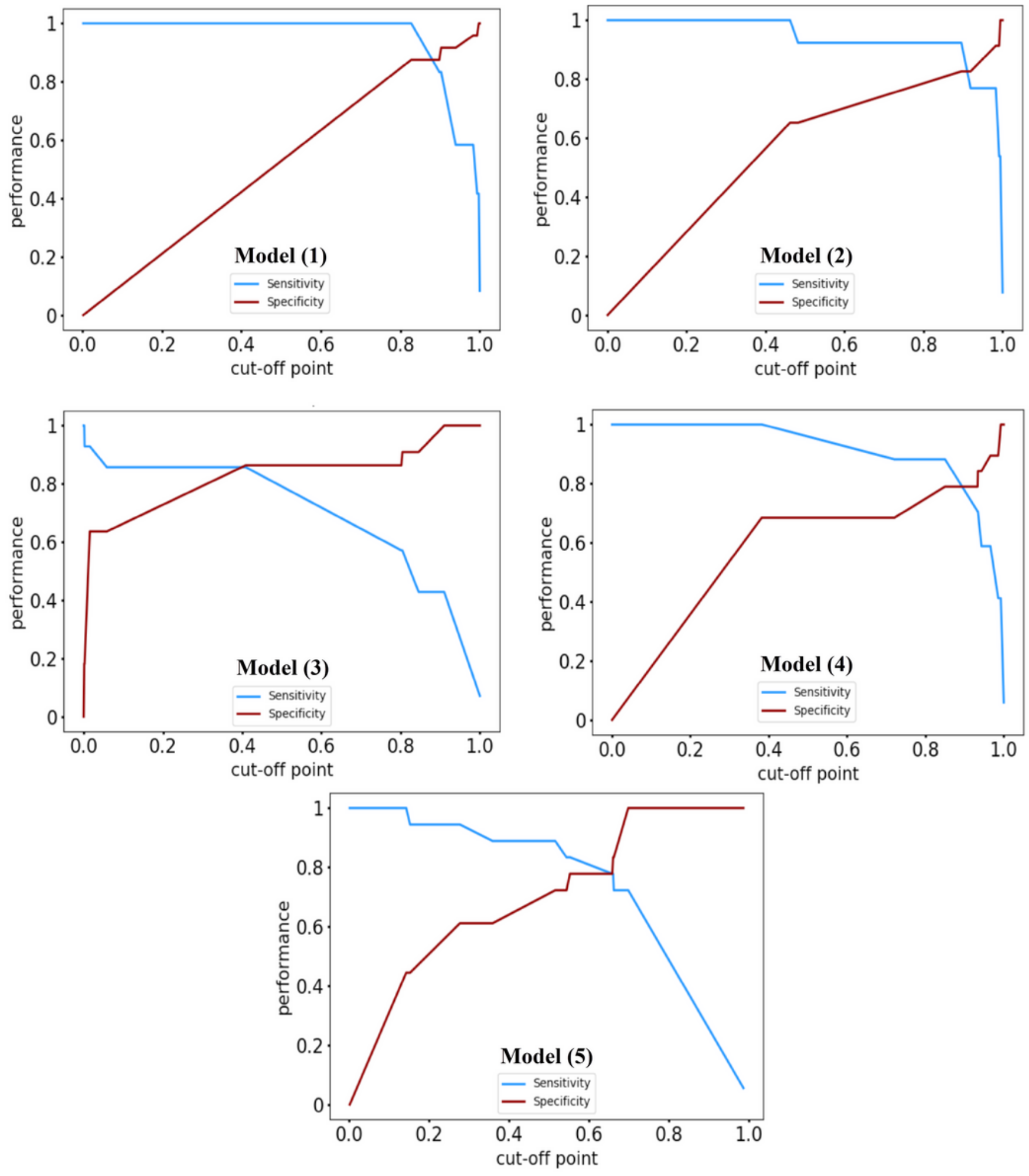

Figure 5

ROC curve analysis of five machine learning models 